\title{
A New High Gain DC-DC Converter With Model- Predictive-Control Based MPPT Technique for Photovoltaic Systems
}

\author{
Omar Abdel-Rahim and Haoyu Wang
}

\begin{abstract}
High step-up DC/DC converter and maximum power point tracking (MPPT) control are essential components in photovoltaic (PV) systems. For the purpose of utilizing PV module in power generation, this manuscript proposes 1-new high stepup DC/DC converter 2-model predictive control based maximum power point tracking (MPC-MPPT) algorithm with optimum number of sensors. The suggested topology is able to provide a voltage gain up to 10 times of input-voltage and its measured efficiency is around $93 \%$. MPC is a prevalent control technique with superior transient and steady-state performances in PV systems. However, in PV DC/DC converters, conventional MPC based MPPT technique typically requires two voltage-sensors and one current-sensor. For the purpose of reducing system cost, this manuscript presents MPC based MPPT technique with twosensors. The algorithm is designed to operate with both fixed and adaptive step-size. Different scenarios and operating conditions are evaluated both in Simulink and with hardware set-up. Results obtained from the simulation and experimental work are consistent and verify the analytical analysis of the system.
\end{abstract}

Index Terms-DC/DC converter, model predictive control based maximum power point tracking (MPC-MPPT).

\section{INTRODUCTION}

$\mathrm{I}_{\mathrm{is}}^{\mathrm{N}}$ photovoltaic (PV) generation systems, a DC/DC converter is required to link the low voltage PV panel and the high voltage DC link. In this DC/DC converter, maximum-powerpoint-tracking (MPPT) control is required to fully exploit the capacity of the PV panel[1]-[2] . In general, high tracking accuracy, and stable transient and steady-state response are important criteria to evaluate the performance of MPPT techniques. In order to achieve such criteria, different MPPT techniques have been investigated in literature [3]-[6].

$\mathrm{P} \& \mathrm{O}$ algorithm is a classical algorithm that detects the maximum power of the PV panel from the slope of the PV curve.

Manuscript received Feburary 2, 2020; revised April 15, 2020; accepted May 8, 2020. Date of publication June 30, 2020; date of current version June 16, 2020.

All authors are with the School of Information Science and Technology, ShanghaiTech University, Shanghai, China.

O. Abdel-Rahim is also with the Electrical Engineering Department, Faculty of Engineering, Aswan University, Aswan 81542, Egypt (e-mail: o.abdelrahim@ aswu.edu.eg).

Digital Object Identifier 10.24295/CPSSTPEA.2020.00016
But the output of the $\mathrm{P} \& \mathrm{O}$ algorithm suffers from oscillation around the maximum power point(MPP) [7], [8]. In [7], the controller speed is optimized during transient by an adaptive scaling factor. In [9], a fixed scaling factor is used to change the perturbation step during the transient. InCond method is a step towards solving the problem of $\mathrm{P} \& \mathrm{O}$ algorithm. It eliminates the oscillation around the MPP and leads to more efficiency. Authors in [10], have developed MPPT technique called delta $\mathrm{P} \& \mathrm{O}$ and a variable step size is suggested to improve MPPT. MPPT technique was developed in [11] based on perturbing the voltage and the duty cycle. $\mathrm{P} \& \mathrm{O}$ algorithm based on the fuzzy logic controller was proposed in [12]. Current-sensorless MPPT technique was proposed in [13], where PV voltage is measured and cell temperature is estimated, and hence PV current could be calculated from a pre-specified look-up table [14], However this technique suffers from complexity and reliability problem. Due to difficulties of ambient temperature estimation and model accuracy.

The technique proposed in [15] is able to omit one current sensor. PV current sensor, by estimating its value from the two measurable states $V_{\mathrm{PV}}\left(\mathrm{PV}\right.$-voltage) and $i_{L}$ (output-inductorcurrent). Although its effectiveness and ability to truck the maximum power, special considerations are required for system stability.

In systems that require multivariable control, finite-set model predictive control (FS-MPC) becomes a very attractive solution [16]. Model predictive control (MPC) based MPPT has been presented in the literature[17], [18]. MPC based MPPT MPC based MPPT methodology presented in [18] is able to track the maximum power of PV-module efficiently at various environmental condition. However it uses three-sensors, two voltage-sensors and one current sensor.

In ideal cases, traditional boost converter is able to provide an infinite boosting ratio, but this is not the practical case [19], [20]. For achieving high step-up ability with high efficiency a lot of research has been done in the literature [21]-[23]. Cascaded boost converter [24] is a nonisolated DC/DC converter that is able to boost low input voltage to a higher level without using high duty cycle. On the other hand, a high rating switch is required due to its high voltage stress. Topologies with switched inductor and/or switched capacitor are good solution in providing high boosting ratio without the need for extreme duty cycle 


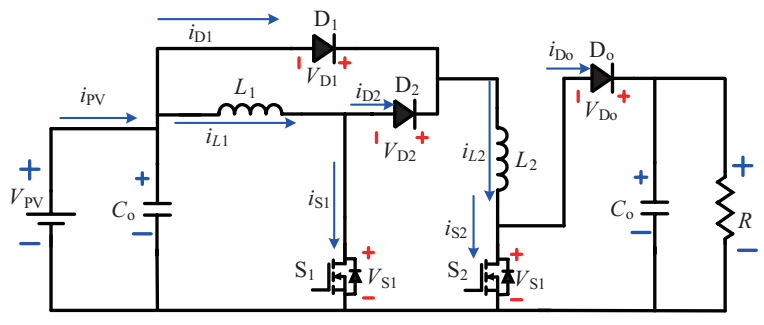

Fig. 1. New high step-up DC-DC converter.

[25], [26].The voltage-lift technique is another modification to achieve high step-up capability. It has several advantages such as: low voltage stress on the active device, and high voltage gain. However, several diode-capacitor stages are required when the conversion ratio are very large, [27]-[29].

Switched inductor introduced in [30], is a transformerless topology able to generate a theoretical boosting ratio of $((1+d) /$ $(1-d)$ ), however switch has voltage stress equal to output voltage and high voltage stress. Similarly, its diodes are under high voltage stress, which may deteriorate overall system efficiency. A similar idea but based on switched capacitor was presented in [31], where inductors were replaced by capacitors. The voltage gain in this case is $(2 /(1-d))$. Hybrid switched inductor-capacitor was introduced to combine the advantages of switched inductor and switched capacitor configurations [32], [33]. Quadratic boost converter introduced in [34] provides higher step-up ration compared to switched inductor or switched capacitor, but with higher current stress on its power-switch. Switched inductor quadratic boost converter proposed in [18] is a combination of topologies exist in [26] and [34] are able to generate high step-up ratio, however the power-switches are under high voltage stress and current stress, which deteriorate its efficiency.

The contribution of this paper is as follow: (1) Proposing and implementing a new high step-up transformerless DCDC converter; (2) Proposing a novel model predictive control maximum power powering tracking (MPC-MPPT) control algorithm with optimum number of sensors based on fixed and adaptive step-size. The proposed MPC-MPPT algorithm has advantage over the technique presented in [18] that outputvoltage sensor is omitted and replaced by a voltage observer to reduce the system cost, meanwhile it keeps the same better performance. Another feature for the developed MPC-MPPT algorithm that the step size could be set to be fixed or adaptive.

\section{New High Gain DC/DC Converter}

The configuration of the new high step-up DC/DC converter is illustrated in Fig. 1. It consists of two inductors, three diodes, one output capacitor and two power switches. In continuous conduction mode (CCM), the converter has two modes of operation depending on the switch status, $S=\{0$ or 1$\}$. Upcoming paragraphs investigates the analysis of operation modes with taking into consideration the ideal characteristic of the circuit components. Operating waveforms of the converter is illustrated in Fig. 2. The two switches are triggered and turned off simultaneously. And hence, the two inductors are charging in operation mode and steady-state analysis, with assumption

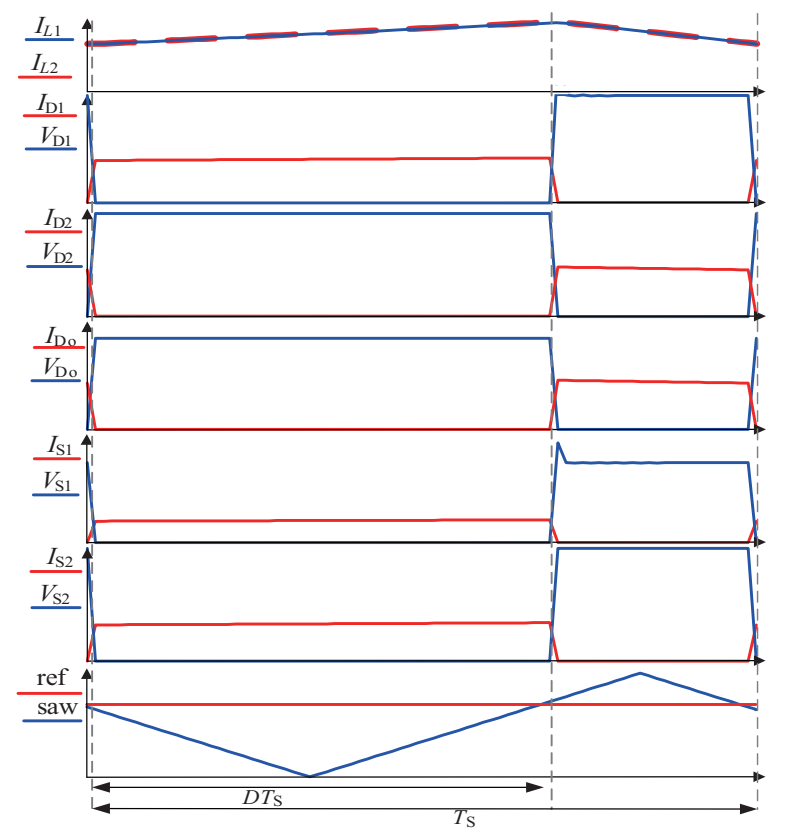

Fig. 2. New converter ideal key waveforms.

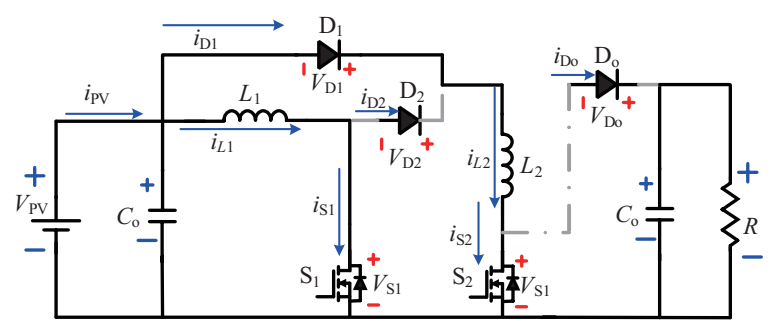

Fig. 3. Operation analysis of the proposed DC-DC converter, mode I.

of ideal parameters and inductors $L_{1}$ and $L_{2}$ are having the same inductance value, are as follows:

\section{A. Mode I}

Mode I occurs as a result of triggering the two switches with high pulse signal, and hence they are turned on. As drawn in Fig. 3, once the switches are turned on, diodes $\mathrm{D}_{2}$ and $\mathrm{D}_{\mathrm{o}}$ are turned off. And hence, inductors $L_{1}$ and $L_{2}$ are charging from the DC source. The characteristics equations of this mode are as follows:

$$
\left\{\begin{array}{l}
v_{L 1}(t)=V_{\mathrm{PV}} \\
i_{\mathrm{PV}}(t)=C_{\mathrm{PV}} \frac{\mathrm{d} V_{\mathrm{PV}}}{\mathrm{d} t}+2 i_{L 1} \\
v_{\mathrm{L} 2}(t)=V_{\mathrm{PV}} \\
C_{\mathrm{o}} \frac{\mathrm{d} V_{\mathrm{o}}}{\mathrm{d} t}=i_{\mathrm{Co}}=-V_{\mathrm{o}} / R
\end{array}\right.
$$

\section{B. Mode II}

Mode II occurs as a result of triggering the two switches with low pulse signal, and hence they are turned off. As seen from 


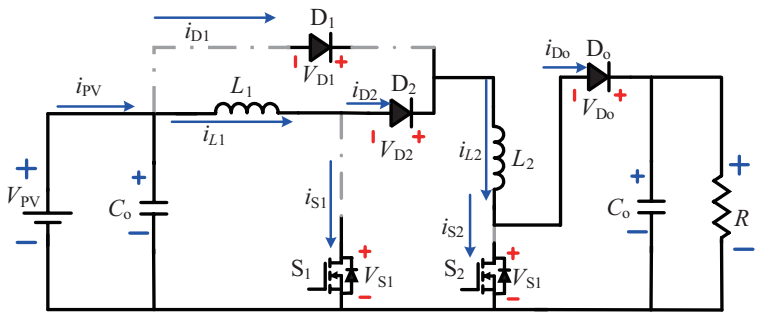

Fig. 4. Operation analysis of the proposed DC-DC converter, mode II.

Fig. 4, once the switches are turned off, diodes $\mathrm{D}_{2}$ and $\mathrm{D}_{\mathrm{o}}$ are turned on to provide a path for the inductor currents and diode $\mathrm{D}_{1}$ is turned off. And hence, inductors $L_{1}$ and $L_{2}$ are discharging their energy in series to the output capacitor. The characteristic equations of this mode are as follows: parallel with the aid of diode $D_{1}$ and discharging their energy in series to the load through diodes $\mathrm{D}_{2}$ and $\mathrm{D}_{\mathrm{o}}$. Analysis of modes I and II are repeated every switching cycle. Inductor volt-second balance and capacitor charge balance are the base criteria, we rely on to obtain input-output voltage relation in the upcoming analysis.

$$
\left\{\begin{array}{l}
v_{L 1}(t)=v_{L 2}(t)=\left(\frac{V_{\mathrm{PV}}-V_{\mathrm{o}}}{2}\right) \\
i_{\mathrm{PV}}(t)=C_{\mathrm{PV}} \frac{\mathrm{d} V_{\mathrm{PV}}}{\mathrm{d} t}+i_{L 1} \\
C_{\mathrm{o}} \frac{\mathrm{d} V_{\mathrm{o}}}{\mathrm{d} t}=i_{C o}=i_{L 1}-V_{\mathrm{o}} / R
\end{array}\right.
$$

Applying inductor volt-second balance and capacitor chargebalance leads to

$$
\left\{\begin{array}{l}
<v_{L 1}(t)>=0 \\
<v_{L 2}(t)>=0 \\
<i_{C_{0}}(t)>=0
\end{array}\right.
$$

The relation between output voltage, input voltage, and capacitors can be deduced from (1)-(3),

$$
V_{\mathrm{o}}=\left(\frac{1+D}{1-D}\right) V_{\mathrm{PV}}
$$

(4) is the voltage gain of the converter, where $D$ is the duty cycle of the converter.

Circuit parameter design is based on the amount of ripple desired in the inductor current and capacitor voltages. In order to maintain CCM operation inductor current ripple is designed to be small. Design of each component of the circuit is given in the upcoming sections.

\section{Inductor $L_{1}$ and $L_{2}$ Design}

The two inductors are symmetrical, with the same inductance value, and they carry the same current (see Fig. 2), one of

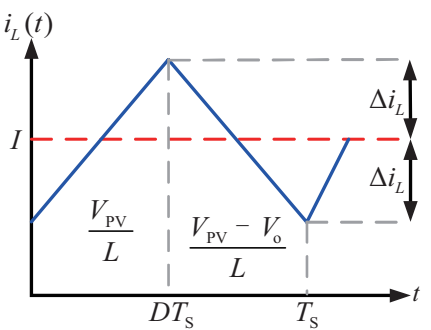

Fig. 5. Inductor $L_{1}$ and $L_{2}$ currents.

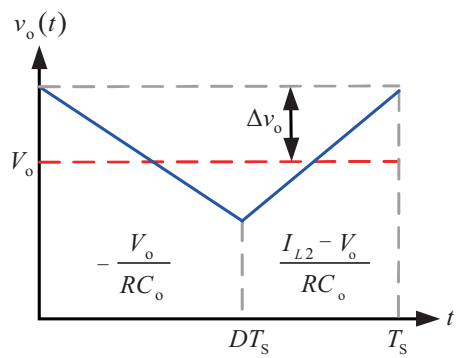

Fig. 6. Capacitor $C_{\mathrm{o}}$ output voltage.

the inductor currents is sketched in Fig. 5. During the first subinterval, the change in inductor current, $2 \Delta i_{L}$, is equal to the slope multiplied by the length of the subinterval value,

$$
\begin{gathered}
2 \Delta i_{L}=\left(\frac{V_{\mathrm{PV}}}{L}\right) D T_{\mathrm{S}} \\
L=L_{1}=L_{2}=\left(\frac{V_{\mathrm{PV}}}{2 \Delta i_{L}}\right) D T_{\mathrm{S}}
\end{gathered}
$$

(6) is used to select inductor $L_{1}$ and $L_{2}$ value. Inductors value depend on input voltage $V_{\mathrm{PV}}$, duty cycle $D$, sample time $T_{\mathrm{s}}$ and inductor current ripple $\Delta i_{L}$.

\section{Output Capacitor Design $C_{\mathrm{o}}$}

Likewise, the capacitor voltage waveform can be sketched and an expression derived for the output voltage ripple peak magnitude, $\Delta v_{0}$. The capacitor voltage waveform is sketched in Fig. 6 . The change in the capacitor voltage, $-2 \Delta v_{0}$, is equal to the slope multiplied by the length of subinterval:

$$
\begin{gathered}
\Delta \nu_{\mathrm{o}}=\left(\frac{V_{\mathrm{o}}}{2 R C_{\mathrm{o}}}\right) D T_{\mathrm{S}} \\
C_{\mathrm{o}}=\left(\frac{V_{\mathrm{o}}}{2 R \Delta v_{\mathrm{o}} C_{\mathrm{o}}}\right) D T_{\mathrm{S}}
\end{gathered}
$$

(8) is used to select the output capacitor value. It is value depends on output voltage $V_{\mathrm{o}}$, duty cycle $D$, sample time $T_{\mathrm{s}}$ and capacitor voltage ripple $\Delta v_{0}$.

A comparison between the proposed converter and other similar topologies exist in the literature in point of view of voltage gain and devices voltage stress is presented in Table I. 
TABLE I

Comparison OF STEP Up Topologies

\begin{tabular}{|c|c|c|c|c|c|c|c|c|}
\hline \multicolumn{2}{|c|}{ Topology } & Boost & SL-boost & SC-boost & [35] & Interleaved & Quadratic & Proposed \\
\hline \multicolumn{2}{|c|}{ No. switches } & 1 & 1 & 1 & 2 & 2 & 1 & 2 \\
\hline \multicolumn{2}{|c|}{ No. diode } & 1 & 4 & 3 & 3 & 3 & 3 & 3 \\
\hline \multirow{2}{*}{\multicolumn{2}{|c|}{ Voltage gain }} & 1 & $\underline{1+D}$ & 1 & $\underline{3+D}$ & 1 & $\left(\frac{1}{1}\right)^{2}$ & $\underline{1+D}$ \\
\hline & & $1-D$ & $\overline{1-D}$ & $\overline{1-D}$ & $\overline{1-D}$ & $\overline{D(1-D)}$ & $(\overline{1-D})$ & $\overline{1-D}$ \\
\hline \multirow{4}{*}{$\begin{array}{l}\text { Switch } \\
\text { stress }\end{array}$} & $\mathrm{S}_{1}$ & $V_{\mathrm{o}}$ & $V_{\mathrm{o}}$ & $V_{\mathrm{o}} / 2$ & $\left(V_{\mathrm{o}}+V_{\text {in }}\right) / 4$ & $V_{\mathrm{o}} / 2$ & $V_{\mathrm{o}}$ & $\left(V_{\mathrm{o}}-V_{\text {in }}\right) / 2$ \\
\hline & $\mathrm{S}_{2}$ & N/A & N/A & N/A & $\left(V_{\mathrm{o}}+V_{\text {in }}\right) / 4$ & $D(1-2 D) V_{\mathrm{o}}$ & $\mathrm{N} / \mathrm{A}$ & $V_{\mathrm{o}}$ \\
\hline & $\mathrm{S}_{3}$ & N/A & N/A & $\mathrm{N} / \mathrm{A}$ & N/A & N/A & N/A & N/A \\
\hline & $\mathrm{S}_{4}$ & N/A & N/A & N/A & N/A & $\mathrm{N} / \mathrm{A}$ & $\mathrm{N} / \mathrm{A}$ & N/A \\
\hline \multirow{4}{*}{$\begin{array}{l}\text { Diode } \\
\text { stress }\end{array}$} & $\mathrm{D}_{1}$ & N/A & $V_{\text {in }}$ & N/A & $\left(V_{\mathrm{o}} / 2\right)+V_{\text {in }}$ & $V_{\mathrm{o}} / 2$ & $V_{\mathrm{o}}(1-D)$ & $\left(V_{\mathrm{o}}+V_{\text {in }}\right) / 2$ \\
\hline & $\mathrm{D}_{2}$ & $\mathrm{~N} / \mathrm{A}$ & $\left(V_{\mathrm{o}}-V_{\text {in }}\right) / 2$ & N/A & $V_{\mathrm{o}} / 2$ & $V_{\mathrm{o}} / 2$ & $D V_{\mathrm{o}}$ & $V_{\text {in }}$ \\
\hline & $\mathrm{D}_{3}$ & N/A & $\left(V_{\mathrm{o}}-V_{\text {in }}\right) / 2$ & N/A & N/A & $\mathrm{N} / \mathrm{A}$ & $\mathrm{N} / \mathrm{A}$ & N/A \\
\hline & $D_{0}$ & $V_{\mathrm{o}}$ & $V_{\mathrm{o}}$ & $\left(V_{\mathrm{o}} / 2\right)$ & $\left(V_{\mathrm{o}}+V_{\text {in }}\right) / 2$ & $V_{\mathrm{o}} / 2$ & $V_{\mathrm{o}}$ & $V_{\mathrm{o}}$ \\
\hline
\end{tabular}

\section{Proposed MPC Based PV MPPT Algorithm}

MPC presents a superior controller for plants, in the suggested application the plant represents the DC-DC converter, that require multiple state-variables needing to be controlled. MPC treats the plant as a finite set of linear models. Each model represents a switching state. MPC calculates the prediction of every switching state, then the minimization process occurs by the cost function, state that gives the minimum error is generated and applied to the plant [35],[36]. The suggested plant in PV system is the DC-DC converter, and due to continuous conduction operation, it has only two-state variables. Hence, a discrete-time model for the proposed DC/DC step-up converter is derived by applying forward Euler method to (1), switch on, and (2), switch off.

$$
\begin{gathered}
I_{\mathrm{PV}}^{1}(k+1)=\left(\frac{2 T_{\mathrm{S}}}{L_{1}}\right) V_{\mathrm{PV}}(k)+I_{\mathrm{PV}}(k) \\
I_{\mathrm{PV}}^{0}(k+1)=\left(\frac{T_{\mathrm{S}}}{2 L}\right)\left[V_{\mathrm{PV}}(k)-V_{\mathrm{o}}\right]+I_{\mathrm{PV}}(k)
\end{gathered}
$$

Where $T_{\mathrm{s}}, L, V_{\mathrm{PV}}(k), I_{\mathrm{PV}}(k), V_{\mathrm{o}}, I_{\mathrm{PV}}^{0}(k+1), I_{\mathrm{PV}}^{1}(k+1)$ are sampling time, inductance, voltage of PV, current of PV, output voltage, predicted PV current if the switch is turned off, and predicted PV current if the switch is turned on, respectively. A quick look to (9) and (10), it is clear that three sensors are required to predict the future value of the PV current. This would increase the system cost and size. (4) is a voltage observer, which is used to calculate the value of the output voltage with the available data of PV voltage and duty cycle. By this methodology, one voltage sensor is removed, which reduces the system cost and at the same time the system performance doesn't affected.

The final step in MPC control is the optimization of the possible future states, and select the optimum value that gives

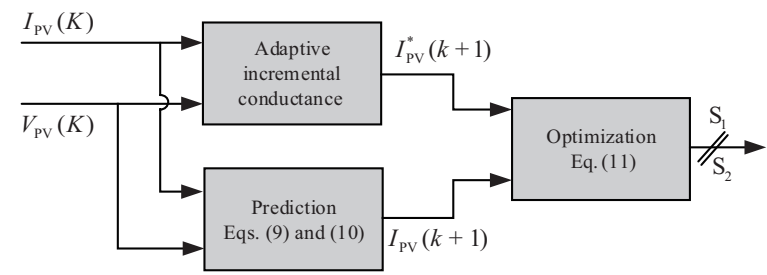

Fig. 7. Control block of the proposed control system.

the minimum error. Optimization is done by cost function:

$$
g^{\sigma=\{0,1\}}=\left|I_{\text {ref }}-I^{\sigma} \mathrm{PV}\right|,
$$

where $g$, and $I_{\text {ref }}$ are the cost function and reference current respectively. Reference current $I_{\text {ref }}$ is generated by incremental conductance algorithm. The proposed control block is depicted in Fig. 7 and MPC-MPPT algorithm is depicted in Fig. 8.

As illustrated in the figures, MPC-MPPT algorithm senses PV current and voltage only, then an incremental conductance approach is applied to generate the reference current that leads to maximum power operation. The MPC algorithm starts to regulate the converter to track the reference current. The capacitor voltage sensor is omitting by the voltage observer, described in the previous section. The perturbation step size, denoted as $Z$, in the flowchart can be set to fixed value to implement a fixed step size MPC-MPPT or it can be designed to be adaptive by the following formula:

$$
Z=C\left|\frac{\Delta I}{\Delta D}\right|
$$

Where $C$ is a scaling factor, $\Delta I$ is the different between current and previous value of $\mathrm{PV}$ current, and $\Delta D$ is the difference between current and previous value of the reference current. 


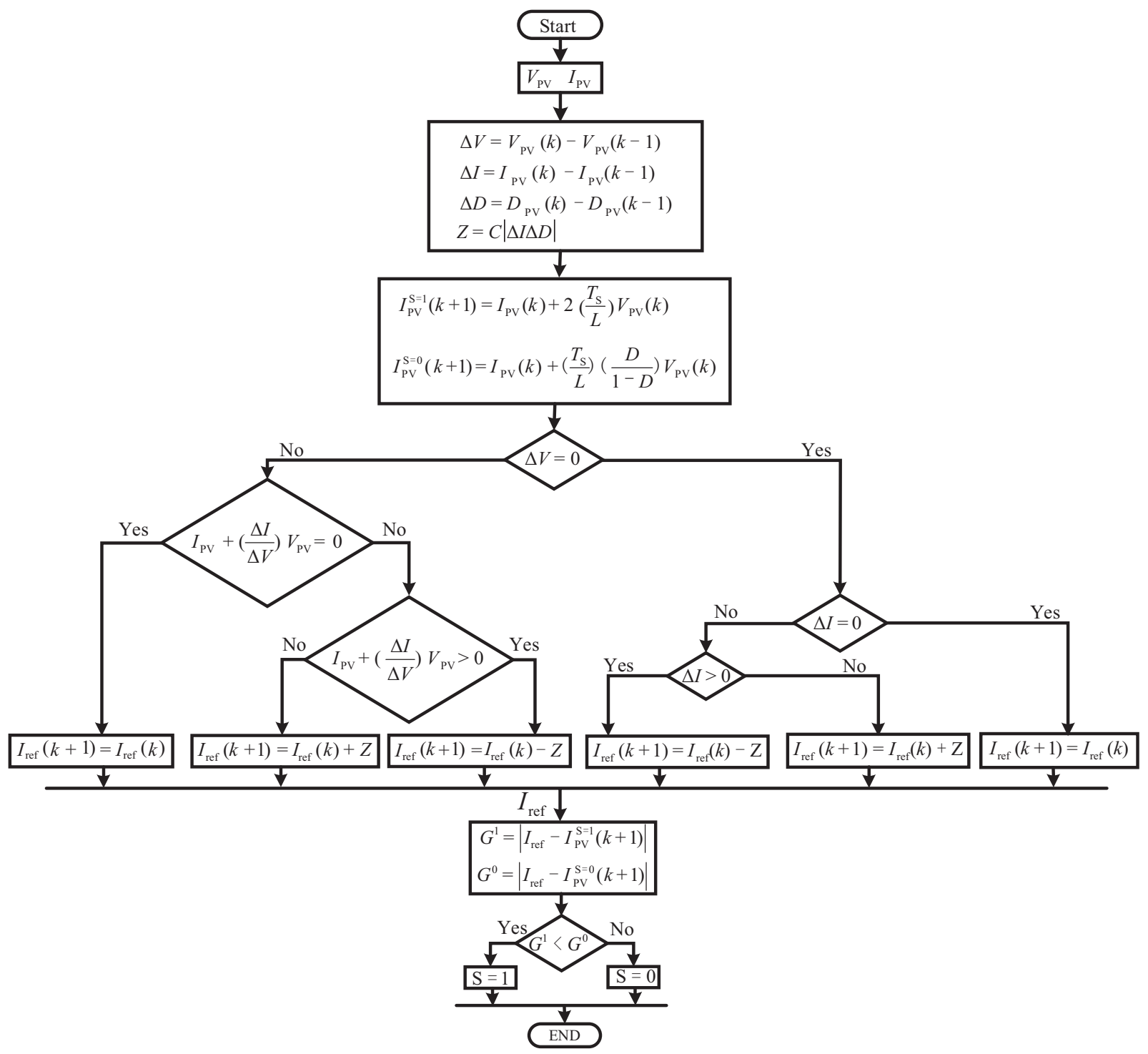

Fig. 8. Proposed MPC based MPPT with reduced number of sensors.

\section{Results AND Discussion}

In order to verify and validate the decent operation of the proposed PV system, proposed DC/DC converter and its reduced sensor MPC-MPPT algorithm, the system is simulated using Simulink and full hardware set-up is demonstrated in laboratory. The developed prototype is depicted in Fig. 9. A $150 \mathrm{~W}$ DC/DC converter prototype is built using parameters in Table II. Dspace 1202 microbox controller is used to implement the proposed MPC-MPPT algorithm with sampling time $T_{\mathrm{s}}$ set to $15 \mu \mathrm{s}$. LEM voltage and current sensors are used to measure voltages and currents. Chroma $62020 \mathrm{H}-150 \mathrm{~S} \mathrm{PV}$ simulator has been used to emulate PV module performance.

Converters assigned to integrate with PV module applications are required to achieve some distinct features such as high voltage gain and higher-efficiency. The proposed converter is designed to operate in CCM, and hence inductor currents

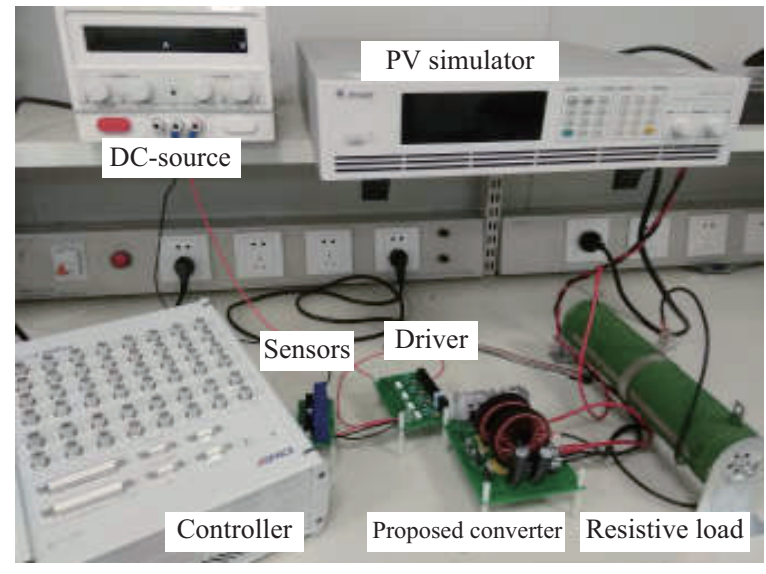

Fig. 9. Hardware prototype of the proposed system.

are always higher than zero, diode $\mathrm{D}_{1}$ is turned on and off in synchronization with the switches, and it has voltage stress less 


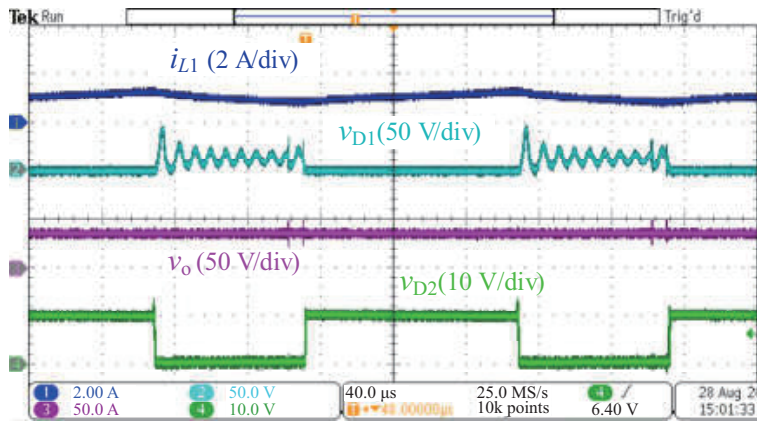

Fig. 10. Converter basic parameters waveforms: Ch1 inductor current, $\mathrm{Ch} 2$ diode D1 voltage, Ch3 output voltage and Ch4 Diode D2 voltage.

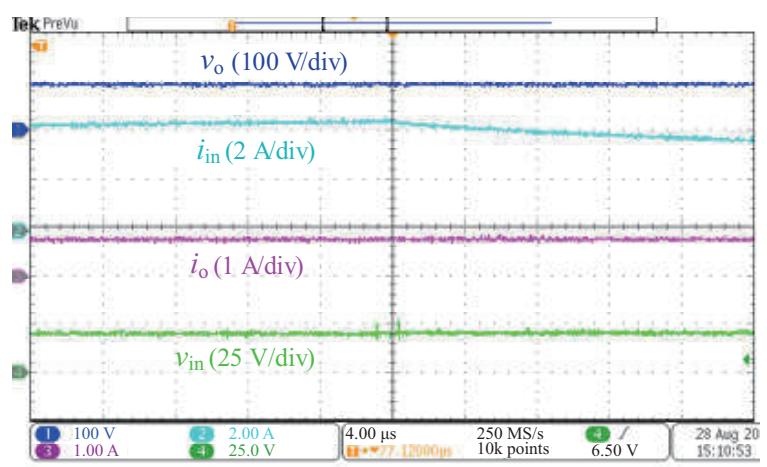

Fig. 11. Case study of step up ratio of 4 with duty cycle set to 0.65 .

than half of the output voltage, while $\mathrm{D}_{2}$ and $\mathrm{D}_{\mathrm{o}}$ conduct in a complementary manner, see Fig. 10. A boosting ratio check case of study is depicted in Fig. 11. In the case of the study, the input voltage is set to $20 \mathrm{~V}$ and duty cycle control to 0.65 , the output voltage is measured around $100 \mathrm{~V}$, step-up ratio, more than 4 times.

Efficiency is a very important factor for better selection and operation of any DC/DC converter. Proposed system efficiency is calculated analytically and measured experimentally. In both analytical calculation and measurement, parameters depicted in Table II are used. Measured efficiency of the proposed converter at different power level is depicted in Fig.12. The converter gives acceptable performance and measured efficiency around 92\%. The proposed converter has similar component counts and voltage gain ability as topology presented in [26], However, the maximum measured efficiency reported for the topology was found $90 \%$ and reduced with increase in boosting ratio to be less than $88 \%$ at $40 \mathrm{~W}$. While the proposed configuration shows maximum measured efficiency $94 \%$ and reduced to $91 \%$ at $100 \mathrm{~W}$ under 4 boosting ratio. Quadratic boost converter is able to provide higher boosting ratio than the proposed converter in this paper, however reported efficiency of quadratic boost converter is round $80 \%$ [37] and its switch current stress is very high compared to the converter proposed in this paper.

Efficient maximum power point tracking is an important factor to make use of photovoltaic generation. The more
TABLE II

Hardware Protototype Parameters

\begin{tabular}{lc}
\hline \hline Components & Parameters \\
\hline PV panel voltage $\left(V_{\mathrm{PV}}\right)$ & $18-40 \mathrm{~V}$ \\
Sampling time & $15 \mu \mathrm{s}$ \\
Circuit inductors $\left(L_{1} / L_{2}\right)$ & $3 \mathrm{mH}$ \\
Input capacitor $\left(C_{1}\right)$ & $260 \mu \mathrm{F}$ \\
Output capacitor $\left(C_{2}\right)$ & $260 \mu \mathrm{F}$ \\
Power MOSFETs $\left(\mathrm{S}_{1-2}\right)$ & IRFP264 \\
Power diode $\left(\mathrm{D}_{1-2}\right)$ & BYV72EW-200 \\
Output diode $\left(\mathrm{D}_{\mathrm{o}}\right)$ & BYV72EW-200 \\
\hline \hline
\end{tabular}

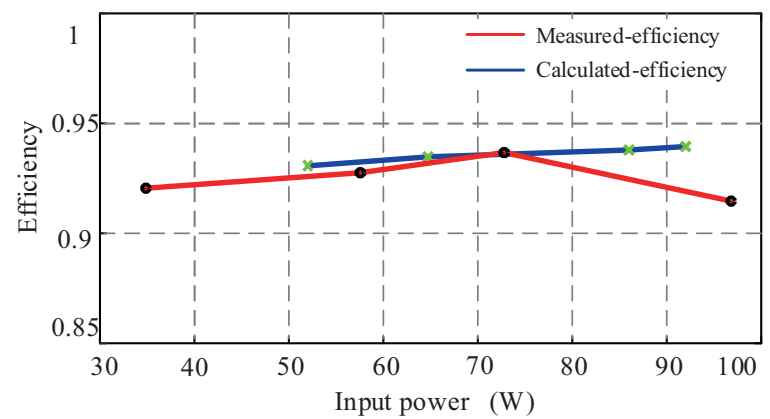

Fig. 12. Converter measured efficiency vs input power under $V_{\text {in }}=20 \mathrm{~V}$, and $M=4$.

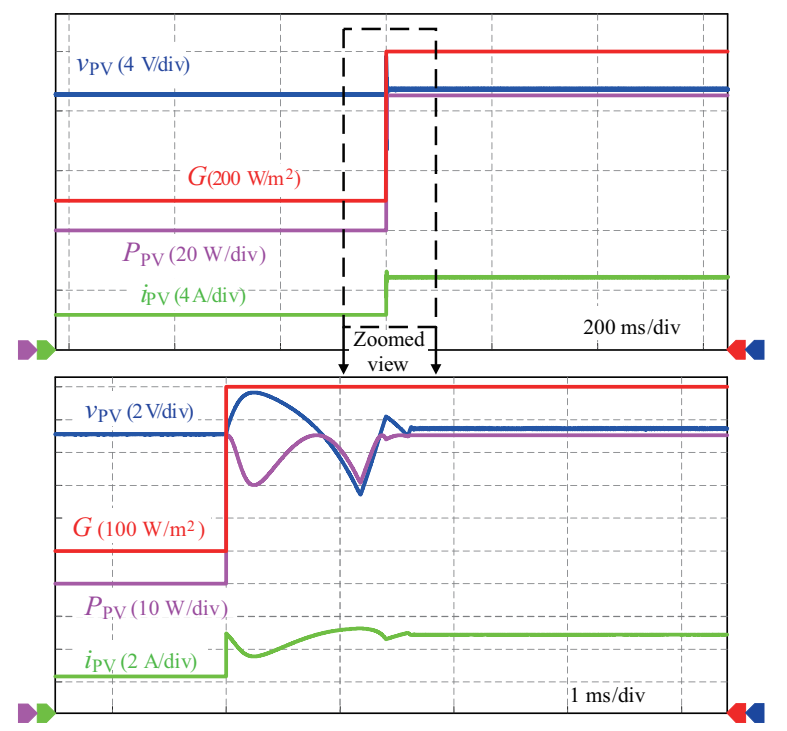

Fig. 13. PV output voltage, current and power with gradual change in solar irradiation.

efficient the MPPT tracker, the more economic operation of the photovoltaic system. The proposed MPC-MPPT algorithm is designed in this paper to operate with a fixed and adaptive step size. The system is studied under normal and weather changing conditions. As has been discussed earlier in this paper, the output characteristic of the PV panels is affected mainly by solar radiation and ambient temperature. But, most influencer is solar radiation. In Fig. 13, an abrupt change in solar radiation is simulated with a change in the radiation $\left(\mathrm{W} / \mathrm{m}^{2}\right)$ from 500 to 1000 . The controller is tracking the maximum power under 


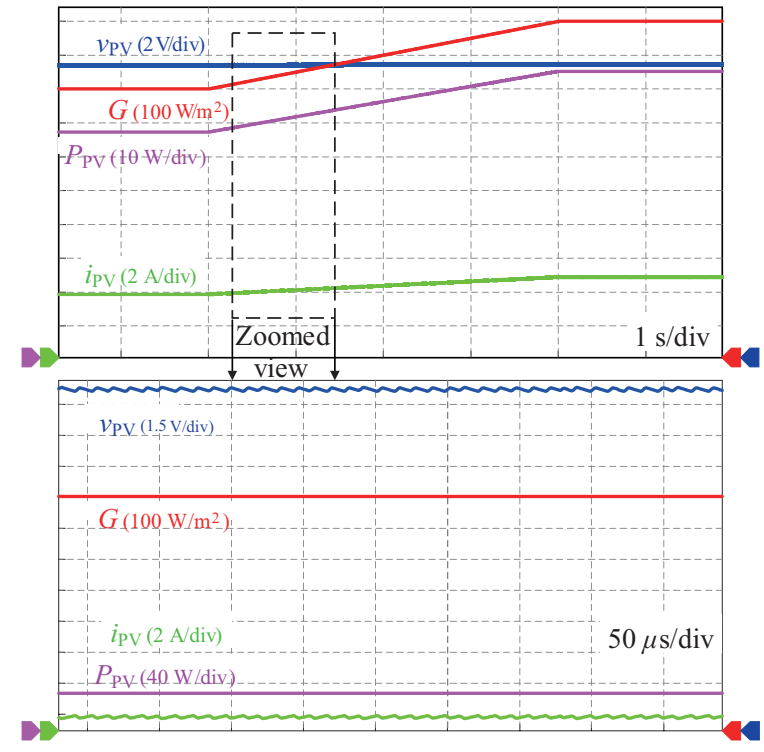

Fig. 14. PV output voltage, current and power with an abrupt change in solar irradiation.

all condition with efficiency more than $99.5 \%$. In most of the real cases, the change in solar radiation is not abrupt, it has a gradual change, for example, a moving cloud or accumulated sand. To take this point into account, a gradual change in solar radiation is simulated in Fig. 14. The controller is acting is a very superior way and able to track the maximum power in very high-efficiency way.

In Fig. 15, PV simulator is programmed to generate PV curve with the following characteristic $\left(P_{\max }=85 \mathrm{~W}, V_{\max }=\right.$ $25 \mathrm{~V}$ and $I_{\max }=3.4 \mathrm{~A}$ ). As the graph illustrates, the algorithm successfully tracks the maximum power. In Fig. 16, where an abrupt change in solar radiation has been taken place. Maximum output power changed according to radiation change from $50 \mathrm{~W}$ to $85 \mathrm{~W}$, then back again to $50 \mathrm{~W}$. The algorithm successfully tracks the maximum power at all conditions as illustrated in the figure.

Figs. 17 and 18 present a detailed comparison between the proposed MPC-MPC with fixed step size, proposed MPCMPPT with adaptive step size and the well-known IncCond algorithm at different step size. The comparison includes an abrupt change in solar radiation and the gradual change in solar radiation. Fig. 17 represents the comparison between the MPPT methodologies under an abrupt change in radiation, while Fig. 18 demonstrates the comparison among the different techniques at the gradual change in solar radiation. IncCond algorithm is one of the widest algorithms used in PV applications, its operation depends on that the slope of PV curve is zero at the maximum power. Two perturbation step size is selected for the IncCond, 0.05 and 0.05. In Fig. 17, with an abrupt change in solar irradiation $\left(\mathrm{W} / \mathrm{m}^{2}\right)$, radiation changed from 1000 to 800 , the MPPT is tracked by all the MPPT methodologies.

The proposed system performance is almost doesn't change

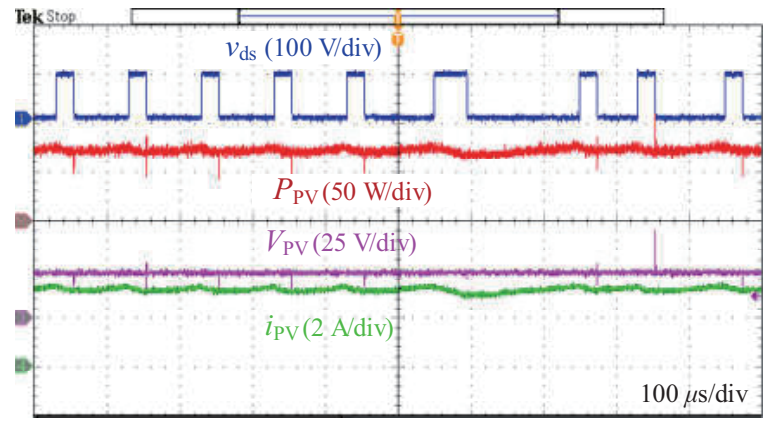

Fig. 15. Case study where PV curve characteristics $\left(V_{\max }=25 \mathrm{~V}\right.$, and $\left.I_{\max }=3 \mathrm{~A}\right)$.

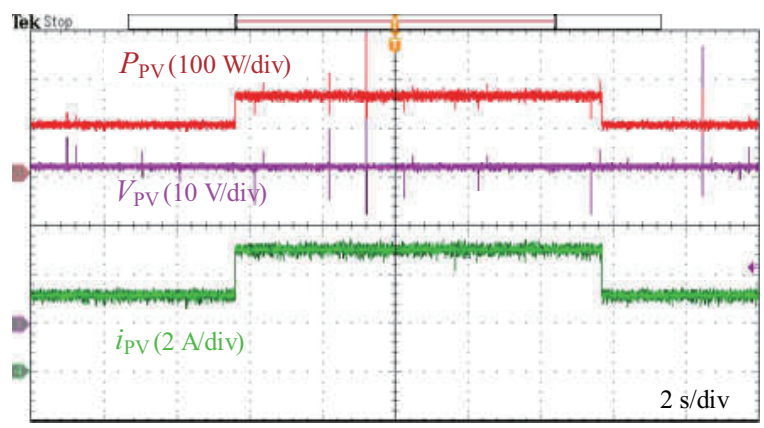

Fig. 16. Abrupt change in solar radiation case of study $P_{\max }$ change from $50 \mathrm{~W}$ to $85 \mathrm{~W}$ and then back to $50 \mathrm{~W}$ again.

with an adaptive or fixed step size. It is able to track the maximum power under all condition with efficiency more than $99.5 \%$. While the performance of the IncCond, greatly affected by the step size. IncCond has big oscillation with step size 0.02 than 0.05 and its efficiency becomes lower. In big systems, this reduction in efficiency may reduce the revenue of the system and the feasibility of the system. In gradually changed solar radiation depicted in Fig. 18. The proposed system has superior performance, almost the same performance with fixed or adaptive step size, while IncCond algorithm depends mainly on the step size.

Step size 0.02 has large ripple and lower efficiency than step size of 0.05 . The main important factors that may affect the selection of one MPPT technique over another one are the complexity of the technique, its efficiency, tracking capability, tracking speed and reliability. A comparison between the proposed methodology and other techniques are depicted in Table III. The proposed system has superior performance such as high efficiency, fastly tracking the maximum power, and reliable technique.

\section{CONCLUSION}

The contribution of this paper could be summarized as follows: (1) Proposing and implementing a new high gain DC-DC converter for PV applications; (2) Developing and implementing MPPT-MPC algorithm with optimum number of sensors for PV applications. The developed DC-DC converter 


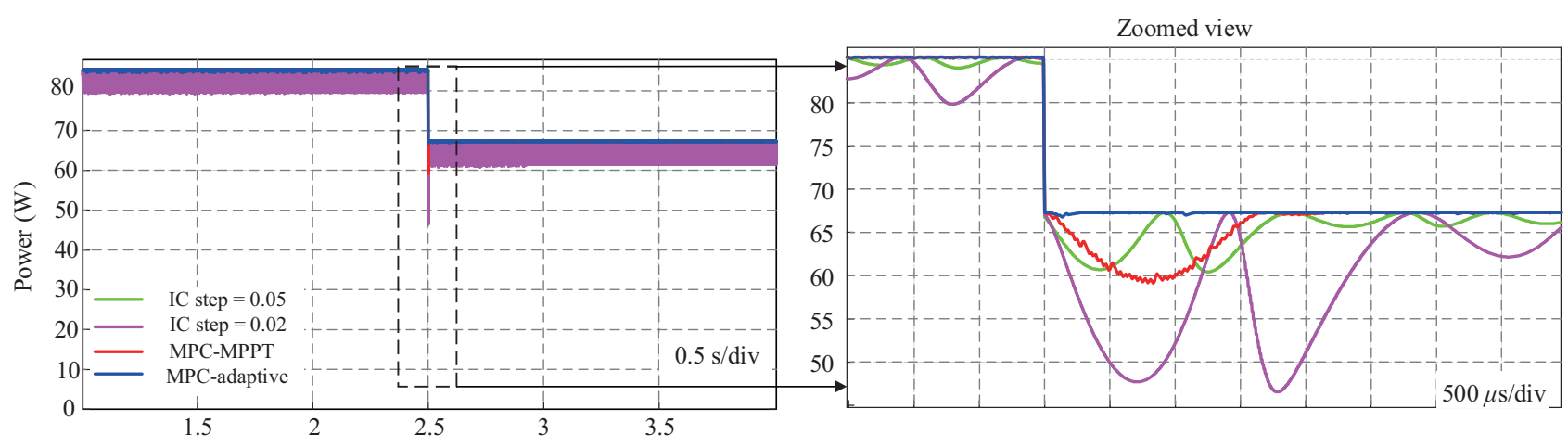

Fig. 17. Comparison between proposed and other MPPT techniques under an abrupt radiation change.

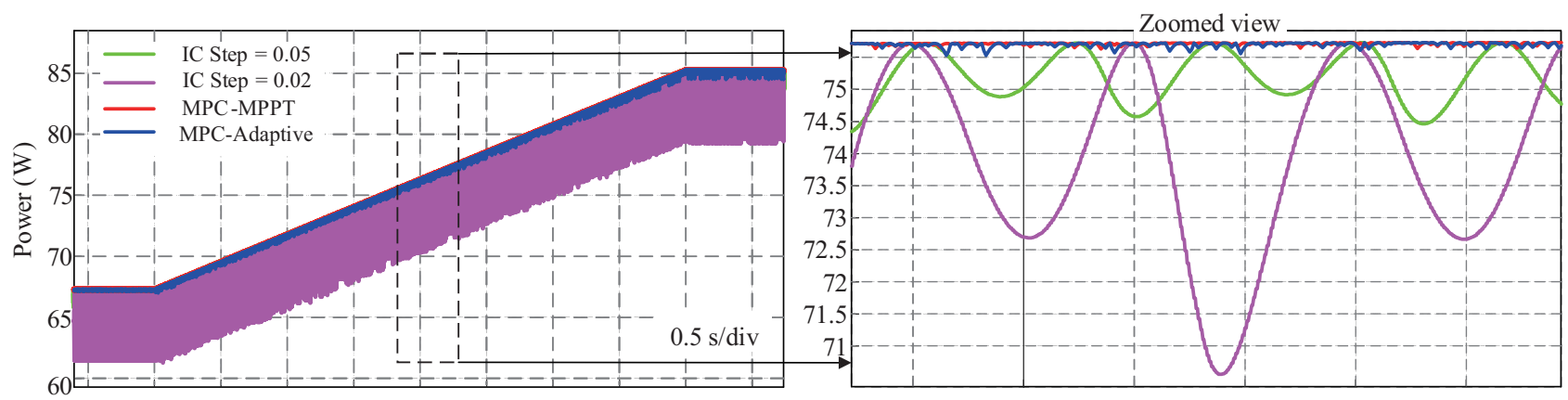

Fig. 18. Comparison among the different techniques at the gradual change in solar radition.

TABLE III

Comparison Among DifFerent MPPT Methodology

\begin{tabular}{|c|c|c|c|c|c|c|c|c|c|}
\hline Evaluated parameters & IncCond & {$[38]$} & $\mathrm{PSO}[39]$ & $\begin{array}{l}\text { Fractional } \\
\text { Isc }\end{array}$ & $\begin{array}{c}\text { Fractional } \\
\text { Voc }\end{array}$ & $\begin{array}{c}\text { Hill } \\
\text { climbing }\end{array}$ & $\begin{array}{c}\text { Fuzzy } \\
\text { logic }\end{array}$ & $\begin{array}{c}\text { Neural } \\
\text { network }\end{array}$ & Proposed \\
\hline Complexity & Simple & Moderate & Moderate & Moderate & Simple & Simple & High & High & Moderate \\
\hline Tracking capability & Moderate & Moderate & Moderate & Moderate & Moderate & Moderate & High & High & High \\
\hline Tracking speed & High & Moderate & Moderate & Moderate & Moderate & Moderate & High & High & High \\
\hline Steady-state oscillation & Yes & No & No & Yes & Yes & Yes & No & No & No \\
\hline Response to load variation & Moderate & Moderate & Moderate & Low & Low & Moderate & Moderate & Moderate & Fast \\
\hline
\end{tabular}

was having superior advantaged over its transformerless counterparts as demonstrated through the manuscript. The developed MPC-MPPT algorithm, output voltage sensor has replaced by an observer to optimize the system cost and at the same time preserve the same performance. Another advantage of the developed algorithm that it could work with fixed and adaptive step-size. Although the superior performance of the proposed MPC-MPPT algorithm, working with variable switching frequency uneased the optimum design of the power converter. Both simulation and experimental results are consistence and agreed with the analytical analysis.

\section{REFERENCES}

[1] D. Divan and P. Kandula, "Distributed power electronics: an enabler for the future grid," in CPSS Transactions on Power Electronics and Applications, vol.1, no.1, pp. 57-65, Dec. 2016.
[2] Y. Yang, A. Sangwongwanich, and F. Blaabjerg, "Design for reliability of power electronics for grid-connected photovoltaic systems," in CPSS Transactions on Power Electronics and Applications, vol.1, no.1, pp.92103, Dec. 2016

[3] J. P. Ram, T. S. Babu, and N. Rajasekar, "A comprehensive review on solar PV maximum power point tracking techniques," in Renewable \& Sustainable Energy Reviews, vol. 67, pp. 826-847, 2017.

[4] A. Sangwongwanich, G. Angenendt, S. Zurmühlen, Y. Yang, D. Sera, D. U. Sauer, and F. Blaabjerg, "Enhancing PV inverter reliability with battery system control strategy," in CPSS Transactions on Power Electronics and Applications, vol.3, no. 2, pp.93-101, Jun. 2018.

[5] A. Bag, B. Subudhi, and P. K. Ray, "An adaptive sliding mode control scheme for grid integration of a PV system," in CPSS Transactions on Power Electronics and Applications, vol. 3, no.4, pp. 362-371, Dec. 2018.

[6] H. Wang, W. Wu, S. Zhang, Y. He, H. S. Chung, and F. Blaabjerg, "A modified Aalborg inverter extracting maximum power from one PV array source," in CPSS Transactions on Power Electronics and Applications, vol. 4, no. 2, pp.109-118, Jun. 2019. 
[7] Q. Mei, M. Shan, L. Liu, and J. M. Guerrero, "A novel improved variable step-size incremental-resistance MPPT method for PV systems," in IEEE Transactions on Industrial Electronics, vol. 58, no. 6, pp. 2427-2434, Jun. 2011.

[8] Y. Jiang, J. A. Abu Qahouq, and T. A. Haskew, “Adaptive step size with adaptive-perturbation-frequency digital MPPT controller for a singlesensor photovoltaic solar system," in IEEE Transactions on Power Electronics, vol. 28, no. 7, pp. 3195-3205, Jul. 2013.

[9] M. A. Abdourraziq, M. Maaroufi, and M. Ouassaid, "A new variable step size INC MPPT method for PV systems," in Proceedings of 2014 International Conference on Multimedia Computing and Systems (ICMCS), Marrakech, 2014, pp. 1563-1568.

[10] A. Pandey, N. Dasgupta, and A. K. Mukerjee, "High-performance algorithms for drift avoidance and fast tracking in solar MPPT system," in IEEE Transactions on Energy Conversion, vol. 23, no. 2, pp. 681-689, Jun. 2008.

[11] M. A. Elgendy, B. Zahawi, and D. J. Atkinson, "Assessment of perturb and observe MPPT algorithm implementation techniques for PV pumping applications," in IEEE Transactions on Sustainable Energy, vol. 3, no. 1, pp. 21-33, Jan. 2012.

[12] M. A. A. Mohd Zainuri, M. A. Mohd Radzi, A. C. Soh, and N. A. Rahim, "Development of adaptive perturb and observe-fuzzy control maximum power point tracking for photovoltaic boost DC-DC converter," in IET Renewable Power Generation, vol. 8, no. 2, pp. 183-194, Mar. 2014.

[13] M. A. Elgendy, B. Zahawi, and D. J. Atkinson, "Comparison of directly connected and constant voltage controlled photovoltaic pumping systems," in IEEE Transactions on Sustainable Energy, vol. 1, no. 3, pp. 184-192, Oct. 2010

[14] P. S. Samrat, F. F. Edwin, and W. Xiao, "Review of current sensorless maximum power point tracking technologies for photovoltaic power systems," in Proceedings of 2013 International Conference on Renewable Energy Research and Applications (ICRERA), Madrid, 2013, pp. 862-867.

[15] I. S. Kim, M. B. Kim, and M. J. Youn, "New maximum power point tracker using sliding-mode observer for estimation of solar array current in the grid-connected photovoltaic system," in IEEE Transactions on Industrial Electronics, vol. 53, no. 4, pp. 1027-1035, Jun. 2006.

[16] S. C. Ferreira, R. B. Gonzatti, R. R. Pereira, C. H. da Silva, L. E. B. da Silva, and G. Lambert-Torres, "Finite control set model predictive control for dynamic reactive power compensation with hybrid active power filters," in IEEE Transactions on Industrial Electronics, vol. 65, no. 3, pp. 2608-2617, Mar. 2018.

[17] S. Sajadian and R. Ahmadi, "Model predictive-based maximum power point tracking for grid-tied photovoltaic applications using a Z-source inverter," in IEEE Transactions on Power Electronics, vol. 31, no. 11, pp. 7611-7620, Nov. 2016.

[18] O. Abdel-Rahim, H. Funato, and J. Haruna, "Novel predictive maximum power point tracking techniques for photovoltaic applications," in Journal Power Electronics, vol. 16, no. 1, pp. 277-286, 2016.

[19] X. Fang, X. Ding, S. Zhong, and Y. Tian, "Improved quasi-Y-source DCDC converter for renewable energy," in CPSS Transactions on Power Electronics and Applications, vol. 4, no. 2, pp. 163-170, Jun. 2019.

[20] X. Liu, X. Zhang, X. Hu, H. Chen, L. Chen, and Y. Zhang, "Interleaved high step-up converter with coupled inductor and voltage multiplier for renewable energy system," in CPSS Transactions on Power Electronics and Applications, vol. 4, no. 4, pp. 299-309, Dec. 2019.

[21] S. Revathi B. and M. Prabhakar, "Transformerless high-gain DC-DC converter for microgrids," in IET Power Electronics, vol. 9, no. 6, pp. 1170-1179, 2016.

[22] L. Yang, T. Liang, and J. Chen, "Transformerless DC-DC converters with high step-up voltage gain," in IEEE Transactions on Industrial Electronics, vol. 56, no. 8, pp. 3144-3152, Aug. 2009.

[23] M. Forouzesh, Y. P. Siwakoti, S. A. Gorji, F. Blaabjerg, and B. Lehman, "Step-up DC-DC converters: A comprehensive review of voltageboosting techniques, topologies, and applications," in IEEE Transactions on Power Electronics, vol. 32, no. 12, pp. 9143-9178, Dec. 2017.
[24] S. Vighetti, J. Ferrieux, and Y. Lembeye, "Optimization and design of a cascaded DC/DC converter devoted to grid-connected photovoltaic systems," in IEEE Transactions on Power Electronics, vol. 27, no. 4, pp. 2018-2027, Apr. 2012.

[25] Y. Zhang, Y. Gao, L. Zhou, and M. Sumner, "A switched-capacitor bidirectional DC-DC converter with wide voltage gain range for electric vehicles with hybrid energy sources," in IEEE Transactions on Power Electronics, vol. 33, no. 11, pp. 9459-9469, Nov. 2018.

[26] B. Axelrod, Y. Berkovich, and A. Ioinovici, "Switched-capacitor/ switched-inductor structures for getting transformerless hybrid DC-DC PWM converters," in IEEE Transactions on Circuits and Systems I: Regular Papers, vol. 55, no. 2, pp. 687-696, Mar. 2008.

[27] F. L. Luo and H. Ye, "Positive output cascade boost converters," in IEE Proceedings-Electric Power Applications, vol. 151, no. 5, pp. 590-606, Sep. 2004.

[28] Y. Jiao, F. L. Luo, and M. Zhu, "Voltage-lift-type switched inductor cells for enhancing DC-DC boost ability: Principles and integrations in Luo converter," in IET Power Electronics, vol. 4, no. 1, pp. 131-142, Jan. 2011.

[29] W. Li, X. Xiang, C. Li, W. Li, and X. He, "Interleaved high step-up ZVT converter with built-in transformer voltage doubler cell for distributed PV generation system," in IEEE Transactions on Power Electronics, vol. 28, no. 1, pp. 300-313, Jan. 2013.

[30] G. Zhang, B. Zhang, Z. Li, D. Qiu, L. Yang, and W. A. Halang, "A 3-Z-network boost converter," in IEEE Transactions on Industrial Electronics, vol. 62, no. 1, pp. 278-288, Jan. 2015.

[31] X. Zhu, B. Zhang, Z. Li, H. Li, and L. Ran, "Extended switched-boost DC-DC converters adopting switched-capacitor/switched-inductor cells for high step-up conversion," in IEEE Journal of Emerging and Selected Topics in Power Electronics, vol. 5, no. 3, pp. 1020-1030, Sep. 2017.

[32] K. I. Hwu and Y. T. Yau, "High step-up converter based on charge pump and boost converter," in IEEE Transactions on Power Electronics, vol. 27, no. 5, pp. 2484-2494, May 2012.

[33] Y. Zhang, Z. Dong, J. Liu and Y. Liu, "Unified model of high step-up DC-DC converter with multi-cell diode-capacitor/inductor network," in Proceedings of 2016 IEEE Energy Conversion Congress and Exposition (ECCE), Milwaukee, WI, 2016, pp. 1-8.

[34] O. Lopez-Santos, L. Martinez-Salamero, G. Garcia, H. ValderramaBlavi, and T. Sierra-Polanco, "Robust sliding-mode control design for a voltage regulated quadratic boost converter," in IEEE Transactions on Power Electronics, vol. 30, no. 4, pp. 2313-2327, Apr. 2015.

[35] Y. Tang, T. Wang, and Y. He, "A switched-capacitor-based activenetwork converter with high voltage gain," in IEEE Transactions on Power Electronics, vol. 29, no. 6, pp. 2959-2968, Jun. 2014.

[36] M. Tomlinson, H. D. T. Mouton, R. Kennel, and P. Stolze, "A fixed switching frequency scheme for finite-control-set model predictive control-concept and algorithm," in IEEE Transactions on Industrial Electronics, vol. 63, no. 12, pp. 7662-7670, Dec. 2016.

[37] O. López-Santos, L. Martínez-Salamero, G. García, H. Valderrama-Blavi and D. O. Mercuri, "Efficiency analysis of a sliding-mode controlled quadratic boost converter," in IET Power Electronics, vol. 6, no. 2, pp. 364-373, Feb. 2013.

[38] T. L. Nguyen and K. S. Low, "A global maximum power point tracking scheme employing direct search algorithm for photovoltaic systems," in IEEE Transactions on Industrial Electronics, vol. 57, no. 10, pp. 3456-3467, Oct. 2010

[39] K. Ishaque and Z. Salam, "A deterministic particle swarm optimization maximum power point tracker for photovoltaic system under partial shading condition," in IEEE Transactions on Industrial Electronics, vol. 60, no. 8, pp. 3195-3206, Aug. 2013. 


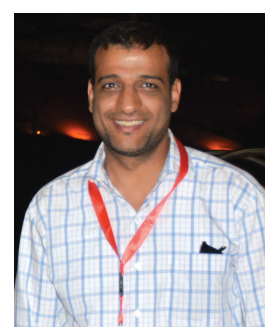

Omar Abdel-Rahim received the bachelor and Master degree in electrical engineering in 2009 and 2012, respectively, from Faculty of Engineering, Aswan University, Egypt, and received his $\mathrm{Ph}$. D. degree from Utsunomiya University, Japan, in 2017. He is currently an Assistant Professor at Faculty of Engineering, Aswan University, and Vice-President of quality Assurance Unit, Faculty of Engineering, Aswan University. From 2009 to 2012, he was with Aswan Power Electronic Application Research Center (APEARC) as a research Assistant since 2010.

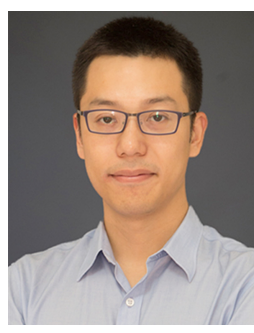

Haoyu Wang received his bachelor degree with distinguished honor in electrical engineering from Zhejiang University in Hangzhou, China. He received his $\mathrm{Ph} . \mathrm{D}$. degree in electrical engineering from the University of Maryland, College Park, MD, USA. $\mathrm{He}$ is currently a tenure track assistant professor in the School of Information Science and Technology at ShanghaiTech University, Shanghai, China. His research interests include power electronics, plug-in electric and hybrid electric vehicles, the applications of wide bandgap semiconductors, renewable energy harvesting, and power management integrated circuits. Dr. Wang is an Associate Editor of IEEE Transactions on Transportation Electrification, and an Associate Editor of CPSS Transactions on Power Electronics and Applications. 